\title{
Nuevos escenarios de la inversión extranjera en Chile ${ }^{1}$
}

\author{
New scenarios for the foreign investment in Chile
}

\section{Jaime Gallegos Zúñiga}

jgallegos@derecho.uchile.cl

Abogado de la Universidad de Chile, Magíster en Derecho de los Negocios Internacionales de la Universidad Complutense de Madrid, Profesor Asistente y Consejero del Departamento de Derecho Económico de la Facultad de Derecho de la Universidad de Chile.

Resumen: El presente artículo busca exponer algunos de los principales elementos introducidos con la ley No 20.848 del 2015, que reemplazó el decreto ley No 600, de 1974, antiguo Estatuto de la Inversión Extranjera, instrumento que cambió significativamente el tratamiento que se brindaba a estas operaciones en América Latina. A tal efecto, se expondrán consideraciones generales respecto de la inversión extranjera, algunos datos de su situación en Chile y también las modificaciones más relevantes que trae la nueva normativa aludida, analizando los derechos que se le reconocen al inversionista extranjero, las instituciones encargadas de fomentar y apoyar este flujo de recursos foráneos, y la Estrategia de Fomento y Promoción de aquélla. A nuestro juicio, especial relieve cobra la referida Estrategia de Fomento y Promoción, la cual debe ser bien diseñada, recogiendo las experiencias foráneas y nacionales que ya se han dado en la materia, a fin de poder aprovechar de mejor manera los beneficios que puede traer consigo esta inyección de recursos externos en la economía nacional.

Palabras clave: Inversión extranjera directa, promoción/estímulo, países en desarrollo.

Abstract: This paper seeks to outline the main elements introduced with law No. 20,848 of 2015, which replaced Decree Law No. 600 of 1974, former Statute of Foreign Investment, which at the time significantly changed the treatment offered to these operations in Latin America. To this end, general considerations will be presented on foreign investment, some facts of their situation in Chile and the main changes that brings the new law, analyzing the recognized rights for foreign investors, institutions responsible for promoting and supporting this flow of foreign resource, and the Strategy for Development and Promotion of the foreign investment. In our view, Strategy Development and Promotion has special importance, which must be well designed, considering the conclusions on foreign and national experiences that have already been given in the matter, in order to better exploit the benefits that could bring this injection of external resources in the national economy.

Key Words: Direct Foreign Investment, promotion / stimulation, developing countries

1 Artículo enviado el 18.04.2016 y aceptado el 25.05.2016. 


\section{Introducción}

El cambio de la normativa local que regula esta clase de operaciones en el país -con ocasión de la dictación de la ley N 20.848, publicada el 25 de junio del 2015 y con vigencia desde el 21 de enero del 2016- sirve de motivación para exponer algunos asuntos dignos de tener en cuenta respecto a esta temática.

Como consideración conceptual previa, creemos oportuno hacer presente que la inversión extranjera directa (IED), en la cual se centrará nuestro análisis, es aquella en que el inversor tiene por objeto el desarrollo de una actividad económica, suponiendo el control o influencia duradera en la dirección y administración de una empresa que opera fuera del territorio en el que reside. Tal modalidad debe diferenciarse de la inversión extranjera indirecta o de portafolio (o de cartera), que implica la adquisición de cuotas en compañías creadas o el manejo crediticio de las mismas, sin que signifique un control significativo de la gestión ${ }^{2}$.

Esta última obedece en muchos casos, a móviles especulativos, y suelen ser capitales que abandonan el país en los momentos de crisis, profundizando algunos problemas económicos del Estado receptor, en razón de lo cual se ha señalado que mientras la IED constituye un "colesterol bueno", la inversión indirecta puede catalogarse como un "colesterol malo"3.

A su vez, es conveniente tener presente que se suele denominar con el anglicanismo de greenfield cuando se produce una adición neta al stock de capital del país receptor, que no se basa en una unidad productiva instalada previamente, sino que a la creación de una empresa nueva ${ }^{4}$.

\section{Importancia de la inversión extranjera}

Generalmente se ha sostenido que la falta de capacidad de ahorro interno ha hecho necesario acudir a los capitales externos ${ }^{5}$. Esta situación ha llevado a que la atracción de recursos

2 José C. Fernández Rozas, Sistema de Derecho Económico Internacional (Cizur Menor: Thomson Reuters, 2010), 368; Elizabeth Paya. "Inversión extranjera directa e innovación: propuestas de reforma al Estatuto de Inversión Extranjera D.L. N ${ }^{\circ}$ 600", en Transposición de normas de la Organización para la Cooperación y Desarrollo Económico a Chile, edit. Cristián Gárate (Santiago: Facultad de Derecho de la Universidad de Chile, 2013), 200.

3 Prakash Loungani y Assaf Razin, “¿Qué beneficios aporta la inversión extranjera directa?”, Finanzas \& Desarrollo (junio, 2011): 7.

4 Ajit Singh, "IED, Globalización y Desarrollo Económico: Hacia la reforma de las reglas del juego nacionales e internacionales", Ekonomiaz 55 (1 er cuatrimestre, 2004): 27; Jaime Turrión y Francisco Velásquez, "La inversión extranjera y las empresas multinacionales", en Lecciones sobre economía mundial. Introducción al desarrollo y a las relaciones económicas internacionales, dir. José A. Alonso (Cizur Menor: Thomson Reuters, 2013), 243; Claudio Rodríguez y Jorge Sánchez, Derecho de los negocios internacionales (Ciudad de México: Porrúa, 2008), 77.

5 Fernández Rozas, Sistema de Derecho Económico Internacional, 370. 
foráneos se transforme en uno de los principales objetivos de política económica de los Estados ${ }^{6}$, motivo por el cual desde inicios de los años ochenta se ha generado una "guerra de incentivos" dirigidos a captar estos flujos de recursos ${ }^{7}$.

El motivo de estas medidas conducentes a atraer esos capitales obedecería a que la "inversión extranjera directa es importante para el crecimiento y el desarrollo de los países receptores de ella. Entre los beneficios que esa inversión genera (...) se encuentran: acceso a capital para el financiamiento de proyectos públicos y privados que requieren altos montos de inversión; acceso a conocimiento o tecnología que crea nuevas capacidades locales o mejora las existentes; formación de recursos humanos en procesos de capacitación y aprendizaje; aumento de la actividad económica y del empleo que corresponde a los procesos de inversión", además de incorporar a las empresas locales en las cadenas de valor internacionales?.

En este mismo orden de consideraciones se ha afirmado que en el contexto de integración mundial de los mercados de capitales, tales inversiones colaboran en el proceso de desarrollo económico, permitiendo la participación en redes internacionales de producción, a raíz de su fragmentación y deslocalización en tal contexto global ${ }^{10}$.

Ahora bien, no obstante los reseñados beneficios que tales divisas traerían consigo, el profesor Ffrench-Davis ${ }^{11}$ ha precisado que los efectos positivos de la inversión extranjera "dependen de que los flujos estén relacionados con una mayor formación de capital y capacidad productiva, y con la transmisión de impulsos de modernización hacia el resto del tejido empresarial", y en una línea similar Singh ${ }^{12}$ hace un llamado a que los gobiernos supervisen y regulen las magnitudes de tales recursos y los tiempos idóneos que la IED implica, puesto que un país tendrá más posibilidades de beneficiarse de la inversión foránea si la integra a sus planes nacionales de desarrollo y tecnología ${ }^{13}$, lo que le permite aprovechar de mejor forma el efecto 'desbordamiento' que se le ha atribuido como cualidad.

6 Ricardo Ffrench-Davis, "La inversión extranjera directa en Chile", en Hacia un Chile competitivo: Instituciones y Politicas, edit. Óscar Muñoz (Santiago: Editorial Universitaria, 2003), 287; Dora Jiménez y Hernando Rendón, "Determinantes y efectos de la Inversión Extranjera Directa: revisión de literatura”, Ensayos de Economia 41 (julio-diciembre, 2012): 110; Lorena Morales, Oriana Guerrero y Mauricio López, "Una evaluación de las políticas promocionales de inversión extranjera directa en América Latina”, Lecturas de Economía 71 (julio-diciembre, 2009): 143-144.

7 Javier Alcalde, "La liberalización de la inversión extranjera directa en América Latina: Un breve enfoque comparativo de Brasil, Chile, Perú y el Grupo Andino”, Apuntes 41 (segundo semestre, 1997): 5-6; Rodríguez y Sánchez, Derecho de los negocios internacionales, 80-82.

8 Biblioteca del Congreso Nacional (en adelante BCN), Mensaje de la Historia de la ley Nº 20.848 (2015), 4; Ministerio de Economía, Fomento y Turismo, Informe de la Comisión Asesora transversal para la Nueva Institucionalidad en Inversión Extranjera, 4, http://www.economia.gob.cl/wp-content/uploads/2015/01/INFORME-INV-EXTRANJERA.pdf (consulta: 2.jun.2016).

$9 \quad \mathrm{BCN}$, Mensaje de la Historia de la ley No 20.848: 25.

10 Roberto Bouzas y Ricardo Ffrench-Davis, "Las condicionantes económicas internacionales y la gobernabilidad de los países en desarrollo", en América Latina en el siglo XXI. De la esperanza a la equidad, coord. Carlos Contreras (Guadalajara: Fondo de Cultura Económica, 1999), 101; Turrión y Velásquez, "La inversión extranjera", 241.

11 Ffrench-Davis, "La inversión extranjera directa en Chile", 306.

12 Singh, "IED, Globalización y Desarrollo", 24-25.

13 Fernández Rozas, Sistema de Derecho Económico Internacional, 379. 
A su turno, Joseph Stiglitz ${ }^{14}$ para referirse a la inversión extranjera, ha dicho que en muchos casos ésta importa una "ambigua bendición", pues si bien se suele indicar que ella genera beneficios como el aporte de conocimientos técnicos, acceso a mercados internacionales, a nuevas posibilidades de empleo y a nuevas fuentes de financiación, en paralelo, en algunas circunstancias ella ha implicado la destrucción de los empresas locales que se ven impedidas de competir con las grandes multinacionales ${ }^{15}$, un insuficiente mejoramiento de las condiciones laborales, falta de acoplamiento de la banca extranjera con las políticas crediticias de las autoridades receptoras, e incluso actos de corrupción perpetrados con la finalidad de obtener tratamientos especiales de las autoridades del Estado receptor, y además, el estímulo a la "enfermedad holandesa", al centrarse tales inversiones en la extracción de determinados recursos en desmedro de la restante actividad exportadora.

Como puede verse la temática de la especie no es pacífica, y de ahí resulte interesante analizar cómo la ha afrontado Chile a través de las diferentes políticas gestadas al efecto.

\section{La inversión extranjera en Chile}

La evolución de los regímenes nacionales de inversión extranjera ha ido de la mano con los contextos históricos y sociales en que éstos se han dado, en razón de que las normas pertinentes han estado en sintonía con el prisma con el que se concibe el rol del Estado en la economía y su relación de estímulo/dirección a la actividad privada.

Respecto a la inversión foránea, en América Latina, ella ha sido planteada por "sus partidarios y detractores tanto como la piedra basal sobre la que se edificará el progreso del país o como la causa de todos nuestros males" ${ }^{\prime 1}$. Así, mientras hace algunos años las naciones en vías de desarrollo tenían políticas hostiles hacia aquella ${ }^{17}$, que se traducían en medidas que procuraban regular y controlar las actividades que se realizaban con esos flujos, desde hace ya un buen tiempo -de modo generalizado desde inicio de la década de los noventa-, esa actitud ha cambiado y paulatinamente se han ido gestando diferentes políticas tendientes a promover masivamente ese ingreso de capitales ${ }^{18}$.

\footnotetext{
Joseph Stiglitz, El malestar de la globalización (Buenos Aires: Taurus, 2002), 106-113.

Fernández Rozas, Sistema de Derecho Económico Internacional, 374-375.

Guillermo Cabanellas, Derecho de las Inversiones Extranjeras (Buenos Aires: Editorial Heliasta S.R.L., 1982), 11.

17 Alcalde, "La liberalización de la inversión extranjera", 13-16; Morales, Guerrero, López, "Una evaluación de las políticas", 149; Osvaldo J. Marzorati, Derecho de los negocios internacionales, vol. 2 (Buenos Aires: Astrea, 2007), 213-254.

18 Singh, "IED, Globalización y Desarrollo", 17; Carlos Ominami. "Fortalezas y debilidades de los mecanismos de inversión extranjera" (conferencia presentada en el seminario "Inversión extranjera hacia Chile y el nuevo enfoque internacional", Santiago, 26 y 27 de marzo de1991, 11).
} 


\subsection{Normativa aplicable a la IED en Chile}

En una secuencia bastante interesante, Rodrígue ${ }^{19}$ revisa las primeras normas en vigor en Chile sobre la materia, y cómo ellas fueron superadas sucesivamente, en los años cincuenta y sesenta, a través de diferentes medidas de estímulo. Estas últimas fueron luego acotadas mediante el establecimiento de restricciones y la fijación de una serie de requisitos, en especial tras la adhesión a la regulación del Pacto Andino, específicamente de su Decisión 24, incorporado a nuestro ordenamiento a través del decreto $\mathrm{N}^{\circ} 482$, de 1971, del Ministerio de Relaciones Exteriores $^{20}$. Finalmente, con la dictación del decreto ley $\mathrm{N}^{\circ}$ 600, de 1974, se establece, de manera pionera en la región ${ }^{21}$, una política de claro incentivo y discriminación positiva en favor del inversionista foráneo.

Además de la preceptiva interna aludida, es menester tener en cuenta que Chile ha celebrado diferentes acuerdos internacionales que han brindado reglas especiales al tratamiento de la inversión extranjera.

En este plano es digno de destacar la suscripción de numerosos acuerdos de promoción y protección recíproca de inversiones (con Argentina, Bolivia, Costa Rica, Cuba, Ecuador, El Salvador, Guatemala, Honduras, Nicaragua, Panamá, Paraguay, Uruguay, Venezuela, Alemania, Austria, Bélgica, Croacia, República Checa, Dinamarca, España, Finlandia, Francia, Grecia, Islandia, Italia, Noruega, Polonia, Portugal, Reino Unido, Rumania, Suecia, Suiza, Ucrania, Filipinas y Malasia), en cuyo mérito se han pactado regímenes convencionales particulares para los inversionistas y los Estados receptores, con un matiz especial, de alcance global, dada la frecuente incorporación de la cláusula de nación más favorecida ${ }^{22}$.

A la clase de instrumentos recién mencionados deben agregarse numerosos tratados de libre comercio, muchos de los cuales, contemplan capítulos referentes a inversión extranjera, y otros

19 Macarena Rodríguez, "Régimen de la inversión extranjera chilena y análisis comparado de los incentivos a la inversión, con especial referencia a Irlanda y Singapur" (tesis de licenciatura, Universidad de Chile, 2003), 4-33.

20 Véase Fernando Morales "Comentarios del Nuevo Estatuto del Inversionista Extranjero", Revista de Derecho Económico 35 y 36 (1971): 59-94, Enrique Piedrabuena, Pacto Andino. Aspectos legales y tributarios (Santiago: Imprenta Fantasía, 1973), 39-114.

21 Morales, Guerrero, López, "Una evaluación de las políticas”, 151; Manfred Wilhelmy y Roberto Durán, "Los principales rasgos de la política exterior chilena entre 1973 y el 2000", Revista de Ciencia Politica XXIII (2, 2003): 273-286; Vittorio Corbo, "Chile: el progreso y las oportunidades", en Chile: una plataforma para la internacionalización (Madrid, Cyan Proyectos Editoriales, 2014), 66.

22 UNCTAD, Bilateral investment treaties 1995-2006: Trends in investment rulemaking (Ginebra: UNCTAD, 2007), 22-26; Rodrigo Polanco, "Transparencia y derechos en arbitrajes internacionales sobre inversión extranjera", Revista de Derecho Económico 75 (2010): 100; Fernández Rozas, Sistema de Derecho Económico Internacional, 391-396; Sebastián López, "La aplicación de la cláusula de la nación más favorecida y del trato justo y equitativo en la jurisprudencia internacional en materia de inversión extranjera. El caso MTD”, Revista Chilena de Derecho 32 (1, 2005): 79-88; Pablo Mahu y Maximiliano Rojas, Arbitraje de inversiones. Los casos chilenos ante el CLADI (2003-2015), (Santiago: Aremi, 2016) 25-70.

Como se sabe, en razón de estos acuerdos que suelen incorporar la cláusula de nación más favorecida, los inversionistas extranjeros no sólo deben atender a la regulación del país receptor y al tenor del convenio bilateral puntual celebrado entre su país y aquel donde se destine la inversión extranjera, puesto que la anotada cláusula le abre la posibilidad de también emplear prerrogativas aún mayores que se hubieren acordado en otros pactos bilaterales de ese tipo. En específico, en lo que atañe a la situación de nuestro país, ello tuvo ocasión de verificarse en la controversia MTD vs. Chile, en que el inversionista extranjero reclamante (de nacionalidad malaya), alegó derechos estipulados en el acuerdo de promoción y protección recíproca de inversiones entre este país y Croacia. 
tantos acuerdos para evitar la doble tributación que, a marzo de 2016, sumaban 26 convenios vigentes $^{23}$, más otros tantos, que aún no están en vigor, suscritos con países como China, Estados Unidos y Japón.

Asimismo, cabe recordar que Chile es signatario de la Convención de Washington, de 1965, que creó el Centro Internacional de Arreglo de Diferencias relativas a la Inversión (CIADI), es miembro del Organismo Multilateral de Garantía de Inversiones (OMGI) y también de la Corporación Financiera Internacional (CFI), todos del Banco Mundial, a lo que se suma su ratificación de la Convención de Nueva York, sobre el Reconocimiento y Ejecución de las Sentencias Arbitrales Extranjeras, en 1975.

Volviendo al referido decreto ley $\mathrm{N}^{\circ}$ 600, podemos decir que éste fue la fuente reguladora principal de ingreso de inversión extranjera en el país ${ }^{24}$, si se le compara con el otro instrumento normativo alternativo aplicable a esa clase de operaciones, el Compendio de Normas de Cambios Internacionales del Banco Central, en especial su Capítulo XIV ${ }^{25}$.

Entre las prerrogativas que, a grandes rasgos, le confería el anotado decreto ley al inversionista extranjero se encontraban:

a) la posibilidad de firmar un contrato ley con el Estado de Chile ${ }^{26}$, en el cual se plasmaban las garantías del inversionista;

b) un régimen de invariabilidad tributaria;

c) acceso al mercado cambiario formal;

d) libertad para repatriar capital luego de un año ${ }^{27}$ de su ingreso al país y para remesar utilidades líquidas obtenidas, y

e) un recurso especial para reclamar la discriminación de que fuera objeto el inversionista extranjero ante el Comité de Inversiones Extranjeras.

23 Servicio de Impuestos Internos, "Convenios Tributarios Internacionales", http://www.sii.cl/pagina/jurisprudencia/convenios.htm (consulta: 20.jun.2016).

24 Ministerio de Economía, Informe de la Comisión, 10-11.

25 "El Capítulo XIV del Compendio de Normas de Cambio Internacionales es un sistema de registro de carácter administrativo, que funciona a través de los bancos comerciales y es administrado por el Banco Central. Las modalidades de inversión que contempla este sistema son los créditos, depósitos, inversiones o aportes de capital provenientes del exterior por una cuantía mínima de 10.000 dólares EE.UU.". "Las únicas condiciones para acogerse a este mecanismo son la obligación de informar y la obligación de utilizar el mercado cambiario formal". Vid. Organización Mundial de Comercio (en adelante OMC), Examen de Politicas Comerciales, Chile (2015), 40.

26 Es menester advertir, en todo caso, que la figura del contrato ley no fue una creación del decreto ley $\mathrm{N}^{\circ} 600$, puesto que esta posibilidad se le brindaba al inversionista extranjero ya con el decreto con fuerza de ley $\mathrm{N}^{\circ} 258$, de 1960 , que fijaba normas sobre inversiones de capitales extranjeros en Chile, cuyo artículo 25 preveía un convenio "en el cual se entenderán incorporados de pleno derecho los beneficios, franquicias y exenciones del decreto supremo que apruebe la inversión".

27 Luego de los cambios introducidos por la ley $\mathrm{N}^{\circ} 19.207$, de 1993 , puesto que antes de ésta el plazo para la repatriación del capital era de tres años. 


\subsection{Inversión extranjera materializada en Chile}

Refiriéndose a nuestro país, el embajador de España, en 2013, ha dicho que en "las últimas dos décadas las instituciones y la economía chilenas han conseguido crear un marco tan favorable, seguro, sólido y previsible que ha situado al país en las más altas cotas de calidad de vida, eficacia económica y transparencia de Iberoamérica. La inversión española ha encontrado en Chile un clima favorable para la inversión exterior, gracias a un entorno de seguridad jurídica, muy por encima de lo encontrado en otros países de la región. En Chile rige un entorno de previsibilidad, de claridad de reglas del juego, de apertura y competitividad que, evidentemente, ha beneficiado al negocio de las empresas que participan en él"28.

En ese contexto, Chile ha sido uno de los principales receptores de inversión extranjera a nivel mundial; prueba de ello es que, de acuerdo con los Informes Mundiales de Inversión de la UNCTAD, se ubicó en el año 2013 en el 17º y el 2014 en el $23^{\circ}$ lugar entre las economías que más IED recibieron en el mundo y en el tercer lugar a nivel latinoamericano" ${ }^{29}$, luego de países con mercados ostensiblemente mayores al local ${ }^{30}$.

En lo relativo al volumen de IED, la inversión pasiva en Chile llegó a los 215.452 millones de dólares EE.UU. a finales de 2014, y estuvo concentrada principalmente en el sector minero (32,4\% del total), servicios financieros $(11,6 \%)$, el sector de electricidad, gas y agua $(7 \%)$, la industria manufacturera $(4,4 \%)$ y las telecomunicaciones $(3,3 \%)$.

Luego, los principales orígenes de las corrientes de capital de inversión entre 2009 y 2013 fueron los países de Europa (36,1\% del total), Estados Unidos (16,7\%) y Brasil (2,7\%)

Es del caso tener en cuenta que esas positivas cifras no se han dado sólo en los últimos años, puesto que Chile fue el país que, en la década de los noventa, contó con la más alta contribución de IED, respecto de su PIB, de toda América Latina ${ }^{32}$.

Ahora bien, es menester precisar que aun cuando las cifras se mantuvieron altas durante toda la referida década de los noventa, en la segunda mitad de ese decenio aquellas se centraron en fusiones y adquisiciones de empresas chilenas ya existentes ${ }^{33}$.

Cabe precisar que fue bajo el alero del decreto ley $\mathrm{N}^{\circ}$ 600, de 1974, que ingresó el grueso (aproximadamente el $80 \%{ }^{34}$ ) de la inversión extranjera durante esos diez años.

28 Iñigo de Palacio, "España e Iberoamérica, una prioridad en la que Chile ocupa un lugar estratégico", en Chile: una plataforma para la internacionalización (Madrid, Cyan Proyectos Editoriales, 2014), 48-49.

29 Ministerio de Economía, Informe de la Comisión, 4-5.

30 Tal nivel de inversiones puede explicarse, entre otras razones, en que si bien el mercado local es reducido, dada la política comercial del país, éste sirve de plataforma para poder exportar en condiciones arancelariamente favorables a diferentes naciones con las cuales Chile ha celebrado tratados de libre comercio y otros acuerdos de similar naturaleza. Vid. Tomás Pablo, "Chile, plataforma para las empresas españolas", en Chile: una plataforma para la internacionalización (Madrid, Cyan Proyectos Editoriales, 2014), 79.

31 OMC, Examen de Políticas Comerciales, Chile, 8-29.

32 Ffrench-Davis, "La inversión extranjera directa en Chile"," 295.

33 Ffrench-Davis, "La inversión extranjera directa en Chile", 297. 
Sin embargo, a partir del año 2002, comenzó a aumentar el porcentaje que ingresaba vía del Compendio de Normas de Cambios Internacionales, con la salvedad de los años 2004 y 2005 , lo que hizo que desde el año 2006 en adelante la utilización del régimen tutelado por el instituto emisor fuera siempre superior al $50 \%$, llegando al $82 \%$ en $2007^{35}$ y ello ha seguido con esa tendencia en lo sucesivo ${ }^{36}$.

Entre otras explicaciones a ese fenómeno, se ha dicho que ello tuvo lugar en razón de la desactivación de los controles cambiarios por parte del Banco Central en 2001 y la adopción de compromisos internacionales, a través de la celebración de los numerosos acuerdos bilaterales ya enunciados, y en el contexto de esta misma causa, que a partir del año 2010, Chile se incorporó a la OCDE, lo que le significó la adopción de diferentes instrumentos de esa organización, como por el ejemplo, su Código de liberalización de los movimientos de capital $^{37}$, en mérito de todo lo cual se garantizaron al inversionista foráneo una serie de prerrogativas y derechos que, en su medida, hicieron inoficioso un régimen de protección especial como el previsto en el decreto ley $\mathrm{N}^{\mathrm{o}} 600^{38}$.

Así las cosas, si bien el decreto ley $\mathrm{N}^{\mathrm{o}} 600$, de 1974, fue considerado como un instrumento moderno, atractivo, que brindaba "gran seguridad, estabilidad y permanencia de las reglas del juego" 39 , y fue seguido de cerca por otros países ${ }^{40}$, las autoridades del Ejecutivo y el Parlamento estimaron que era el momento para derogarlo, por las razones cuantitativas indicadas y por los motivos que se explicarán en el siguiente capítulo.

\section{Modificaciones recientemente efectuadas}

Atendidos una serie de índices internacionales, que sucesivamente han colocado a Chile en una posición de primer orden a nivel latinoamericano, como son el Informe de Competitividad Global, del Foro Económico Mundial; el estudio Doing Business, del Banco Mundial; el Índice de Desarrollo Humano, del Programa de Naciones para el Desarrollo, y los Estudios de percepción de corrupción, de Transparencia Internacional, entre otros tantos, se estimó de que había llegado el momento de afrontar la captación de la inversión extranjera desde otro ángulo.

\footnotetext{
34 Juan Eduardo Chackiel y Valeria Orellana, "Inversión Extranjera Directa en Chile: Mecanismos de Ingreso y Compilación para la Balanza de Pagos", Estudios Económicos Estadísticos del Banco Central de Chile, 109 (2014): 13-14.

35 Chackiel y Orellana, "Inversión Extranjera Directa en Chile", 15, 24.

36 OMC, Examen de Politicas Comerciales, Chile, 29.

37 Chackiel y Orellana, "Inversión Extranjera Directa en Chile", 18.

38 OMC, Examen de Politicas Comerciales, Chile, 39.

39 Ffrench-Davis, "La inversión extranjera directa en Chile", 289; Pablo, "Chile, plataforma para las empresas españolas", 74.

40 Paya, Inversión extranjera directa, 205; Alcalde, "La liberalización de la inversión extranjera”, 29.
} 
De este modo, la nueva normativa en vigor opera sobre la lógica, que ya venía desarrollándose hace bastante tiempo por la doctrina ${ }^{41}$, según la cual resulta más relevante para un inversionista extranjero que el país receptor cuente con estabilidad macroeconómica, certeza jurídica, disponibilidad de infraestructura, y calificación y adaptabilidad de mano de obra, que el otorgamiento de beneficios específicos conducentes a captar esos capitales, en el entendido que los incentivos tributarios no tendrían el mérito de lograr atraer inversiones foráneas por sí solos, si no forman parte de un programa integral que presuponga las cualidades recién mencionadas ${ }^{42}$.

Ahora bien, es necesario advertir que estudios sobre estos asuntos hay muchos y de las más variadas clases $^{43}$, por lo que no puede señalarse, a ciencia cierta, que hay un consenso generalizado y uniforme sobre las reales causas que motivan a un sujeto a invertir sus recursos en otro Estado.

Así las cosas, en la línea adoptada por nuestro legislador, es útil tener en cuenta que la OCDE, en sus recomendaciones respecto de la forma en que los países fomenten la IED, ha enfatizado la importancia de ofrecer a los inversionistas extranjeros condiciones macroeconómicas estables y un marco jurídico no discriminatorio respecto de los inversionistas nacionales. Simultáneamente, ha aconsejado enfocar los esfuerzos de promoción de inversiones hacia sectores estratégicos y hacia aquellos que carecen de inyección de recursos debido a fallas de mercado apropiadamente identificadas. También resalta la necesidad de evitar la competencia tributaria entre países (o regiones) con el objetivo de atraer proyectos de inversión extranjera ${ }^{44}$.

El sistema de concesión de incentivos específicos a los inversionistas extranjeros desde hace un tiempo había sido puesto en tela de juicio, puesto que según afirman algunos autores ${ }^{45}$, esa clase de medidas, de competencia por parte de los países en vías de desarrollo por atraer esos capitales, se traduciría, en muchos casos, en desmantelamiento de su regulación laboral, ambiental e impositiva, generando efectos negativos en los salarios, lo que a la larga se traducía en una dolorosa mera entrega de beneficios a las grandes empresas trasnacionales.

En este mismo orden de ideas, antes de esta reforma en la normativa de inversiones extranjeras, se sostuvo que tales "garantías no deben ser obstáculo para poder efectuar correcciones del sistema tributario y de captación de rentas económicas, y pueden ser un

41 Bouzas y Ffrench-Davis, "Las condicionantes económicas internacionales”, 101-102; Ffrench-Davis, "La inversión extranjera directa en Chile", 320.

42 Morales, Guerrero y López, "Una evaluación de las políticas”, 161-163; Marzorati, Derecho de los negocios internacionales, 206.

43 Fernández Rozas, Sistema de Derecho Económico Internacional, 370-371; Rodríguez y Sánchez, Derecho de los negocios internacionales, 88-92; Turrión y Velásquez, "La inversión extranjera", 245-254.

44 Ministerio de Economía, Informe de la Comisión, 7.

45 Wesley Marshall, "Inversión Extranjera directa y de cartera en América Latina: La carrera financiera a fondo" en Del sur hacia el norte. Economía politica del orden económico internacional emergente, coords. Alicia Girón y Eugenia Correa (Buenos Aires: CLACSO, 2007), 118. 
Nuevos escenarios para la inversión extranjera en Chile Javier Gallegos Zúñiga

incentivo eficaz para estimular la modernización de la economía nacional, la transparencia y el desarrollo productivo" 46 .

Bajo estas premisas generales procede acotar que el artículo $9^{\circ}$ de la ley $\mathrm{N}^{\circ} 20.780^{47}$-de reforma tributaria, que modificó el sistema de tributación de la renta e introdujo diversos ajustes en el sistema tributario- dispuso que a partir del 1 de enero de 2016, se derogaba el decreto ley $\mathrm{N}^{\circ}$ 600, de 1974, Estatuto de la Inversión Extranjera.

A contar de dicha fecha, se dijo, que el Comité de Inversiones Extranjeras no podría celebrar nuevos contratos de inversión extranjera sujetos a las reglas del aludido estatuto, sin embargo ello tuvo una excepción, prevista en el artículo segundo transitorio de la ley $\mathrm{N}^{\mathrm{o}} 20.848$, que se verá más adelante.

Sin embargo, los titulares de contratos de inversión ya suscritos con el referido Comité continúan rigiéndose por las normas legales vigentes aplicables a sus convenios.

\section{Ley $\mathrm{N}^{\mathrm{o}} 20.848$, del 2015, que establece marco para la IED en Chile y crea la institucionalidad respectiva}

Para la gestación del proyecto que se transformaría en la ley en análisis, el Gobierno formó una Comisión Asesora transversal para la Nueva Institucionalidad en Inversión Extranjera (en adelante CANIE) ${ }^{48}$, integrada el Ministro de Economía, Fomento y Turismo y otros trece expertos en la materia, que formularon las propuestas respectivas.

Entrando de lleno en las normas de esta regulación, puede decirse que el artículo $2^{\circ}$ de la ley de que se trata define la inversión extranjera directa (IED), para efectos de esa preceptiva, indicando que aquella es la transferencia al país de capitales extranjeros o activos de propiedad de un inversionista extranjero o controlado por éste, por un monto igual o superior a US\$

46 Ffrench-Davis, "La inversión extranjera directa en Chile", 322.

47 Esta modificación viene ya en el mensaje del proyecto presentado por el Ejecutivo (BCN, Historia de la ley $N^{o}$ 20.780, 11). Sobre este particular, el Ministro de Hacienda de la época señaló, como fundamento a este cambio, que "dicha normativa (...) fue concebida en otro momento de Chile, cuando efectivamente las inversiones extranjeras necesitaban un marco especial, institucional, de estabilidad, para entrar al país.

Claramente, hace muchos años que la inversión extranjera ingresa al país y Chile tiene un estatus reconocido a nivel mundial, no solo por ser miembro de la OCDE, sino por su estabilidad económica, social e institucional, lo que nos da la posibilidad de avanzar y derogar este decreto ley." (BCN, Historia de la ley $\left.N^{o} 20.780,121\right)$.

Con todo, dado que su derogación no supone el ingreso de mayores ingresos a las arcas fiscales, cual es el objetivo perseguido por la citada reforma tributaria, algunos congresistas e invitados al debate parlamentario se mostraron contrarios a derogar ese estatuto, pues se estimaba que tal cambio suponía mermar, en cierta medida, la certeza del ordenamiento jurídico local (BCN, Historia de la ley $\left.N^{\circ} 20.780,717,718,729,936,938,1013,1014\right)$.

48 Ante el referido órgano colegiado expusieron los vicepresidentes ejecutivos del Comité de Inversiones Extranjeras (CIE) y de la Corporación de Fomento de la Producción (CORFO), representantes de la Organización de Cooperación y Desarrollo Económico (OCDE) y de la Central Unitaria de Trabajadores (CUT), el gerente general de la Confederación de la Producción y el Comercio (CPC), y el presidente del Consejo Minero. 
$5.000 .000^{49}$ o su equivalente en otras monedas, que se efectúe a través de moneda extranjera de libre convertibilidad, bienes físicos en todas sus formas o estados, reinversión de utilidades, capitalización de créditos, tecnología en sus diversas formas susceptible de ser capitalizada, o créditos asociados a la inversión extranjera proveniente de empresas relacionadas.

Asimismo, se considera IED aquella superior a la suma señalada, que se transfiera al país y se materialice a través de la adquisición o participación respecto del patrimonio de la empresa o en el capital de la sociedad receptora de la inversión, constituida en Chile conforme a la ley chilena, en forma directa o indirecta, que le otorgue control de, al menos, el 10\% del derecho a voto de las acciones de la sociedad, o de un porcentaje equivalente de participación en el capital social si no se tratare de una sociedad por acciones o en el patrimonio de la empresa de que se trate ${ }^{50}$.

Ahora bien, no obstante el umbral en dólares indicado, es menester tener en cuenta que el inciso tercero del artículo 15 de la ley en análisis previene que la Agencia de Promoción de la Inversión Extranjera debe promover y atraer el ingreso de todo tipo de capitales e inversiones del exterior "sin importar su monto".

En tanto, el artículo $3^{\circ}$ señala que para efectos de esa preceptiva se entiende por inversionista extranjero a toda persona natural o jurídica constituida en el extranjero, no residente ni domiciliada en Chile, que transfiera capitales al país, en los términos recientemente enunciados ${ }^{51}$.

Tal inversionista foráneo puede solicitar un certificado ${ }^{52}$ emitido por la Agencia de Promoción de la Inversión Extranjera, que tiene por única finalidad habilitar el acceso al régimen aplicable al inversionista foráneo, establecido en el párrafo $2^{\circ}$ del Título $\mathrm{I}$, entre los artículos $5^{\circ}$ y $9^{\circ}$ de ese cuerpo legal, que pasamos a revisar.

49 Durante la tramitación del proyecto se indicó que el piso de US $\$ 5.000 .000$ obedece a que de los flujos totales, lo que ingresa por una cantidad menor a esa cifra representa menos del 1\% de los montos de inversión, en razón de lo cual, si se dispone de capital humano y financiero para el tratamiento de esas cantidades habría un uso ineficiente de los recursos públicos (BCN, Historia de la ley $\left.N^{\circ} 20.848,30\right)$.

En tanto, es conveniente hacer presente que en la discusión parlamentaria a la cual fue invitada la representante de la Cámara de Comercio Chileno Norteamericana, esa personera sugirió que no resultaba aconsejable que ese monto se consignase en la ley, ya que hace rígido el asunto, por lo que proponía que tal cifra fuere determinada sucesivamente en la Estrategia de Promoción y Fomento de la Inversión Extranjera (BCN, Historia de la ley $\left.N^{o} 20.848,110\right)$.

50 Esta alusión al 10\% ha sido propuesta por el Fondo Monetario Internacional, para precisar la noción de control en la gestión, que sirve para diferenciar a la IED de la inversión de portafolio o cartera.

51 Dada esta conceptualización, se advirtió durante la tramitación parlamentaria, que se excluye a la persona jurídica constituida en Chile pero sometida a control extranjero o también una alianza entre una sociedad o persona jurídica constituida en el país que se asocie con un ente foráneo (BCN, Historia de la ley $N^{\circ} 20.848,99,158$ ).

52 El objetivo de este documento es reemplazar al contrato ley que se contemplaba en el decreto ley $\mathrm{N}^{\circ} 600$, y a diferencia de ese contrato, este certificado opera por el solo ministerio de la ley (Ministerio de Economía, Informe de la Comisión, 15). 
Nuevos escenarios para la inversión extranjera en Chile Javier Gallegos Zúñiga

\section{1. Régimen aplicable a la IED.}

La normativa local en estudio reconoce una serie de derechos al inversionista extranjero, cuales son:

\subsubsection{Remesar al exterior el capital transferido y las utilidades líquidas generadas}

Según el artículo $5^{\circ}$, el inversionista extranjero tiene derecho a remesar al exterior el capital transferido $^{53}$ y las utilidades líquidas que sus inversiones generen, una vez cumplidas todas las obligaciones tributarias que correspondan según la normativa nacional.

\subsubsection{Acceso al mercado cambiario formal}

El artículo $6^{\circ}$ habilita al inversionista extranjero para que pueda acceder al mercado cambiario formal a fin de liquidar las divisas constitutivas de su inversión, como también para remesar el capital invertido o las utilidades obtenidas, una vez cumplidas todas las obligaciones tributarias que procedan de acuerdo con la normativa nacional.

El inciso final precisa que el tipo de cambio aplicable para la referida liquidación u obtención de las divisas en el mercado cambiario formal será el que libremente acuerden las partes intervinientes.

En tanto, el artículo $7^{\circ}$ puntualiza que las operaciones de cambios internacionales referidas quedan sujetas a las potestades del Banco Central de Chile, de acuerdo a lo establecido en su ley orgánica constitucional y otras leyes especiales.

\subsubsection{Exenciones tributarias para la importación de determinados bienes}

A su turno, el artículo $8^{\circ}$ prescribe que los inversionistas extranjeros están exentos del impuesto sobre las ventas y servicios en la importación de bienes de capital, en la medida que se cumplan con los requisitos y se sujeten a los procedimientos que para estos efectos se establecen en el artículo $12^{\circ}$, letra $\mathrm{B}, \mathrm{N}^{\circ} 10$, del decreto ley $\mathrm{N}^{\circ} 825$, de 1974, es decir, aquellos que se encuentran singularizados en el decreto $\mathrm{N}^{\circ} 370$, de 2006, del entonces Ministerio de Economía, Fomento y Reconstrucción.

\subsubsection{Sujeción al principio de trato nacional}

Por su parte, el artículo $9^{\circ}$ reconoce el principio de trato nacional, al señalar que los inversionistas extranjeros quedan sujetos al régimen jurídico común aplicable a los nacionales, sin que pueda discriminarse arbitrariamente respecto de ellos, sea de manera directa o indirecta.

53 Es necesario hacer presente que los artículos $4^{\circ}$ y $6^{\circ}$ del decreto ley $\mathrm{N}^{\circ} 600$, expresamente eximían la remesa del capital de toda carga tributaria, sin embargo, a diferencia del régimen hoy vigente, se sujetaba esos recursos a una permanencia en el país de al menos un año. 
Revista Tribuna Internacional

Volumen $5 \cdot \mathrm{N}^{\circ} 9 \cdot 2016 \cdot$ pp. 29-51

ISSN 0719-482X (versión en línea)

\subsubsection{Comparación del nuevo régimen con el decreto ley $N^{0} 600$, en lo que se refiere al régimen aplicable al inversionista extranjero.}

Como puede apreciarse, la principal diferencia que se observan del cotejo de esta normativa con la del decreto ley $\mathrm{N}^{\mathrm{o}} 600$ se vincula con la eliminación de la discriminación positiva a favor del inversionista extranjero, que se materializaba a través de la posibilidad de acogerse al contrato $l e y^{54}$, bajo el cual se podía estipular un régimen temporal de invariabilidad tributaria ${ }^{55}$ y además se tenía acceso a mecanismos de impugnación especiales, ajenos al inversionista nacional.

Cabe mencionar que figuras análogas al contrato ley del decreto ley $\mathrm{N}^{\circ} 600$, como mecanismo de incentivo a la inversión extranjera se han establecido en otros países de la región como en el Perú y Colombia ${ }^{56}$. Sin embargo, es menester tener presente que en ese último Estado la ley $\mathrm{N}^{\circ}$ 963, de 2005, de Estabilidad Jurídica ${ }^{57}$, que preveía esa figura, fue derogada el año 2012, mediante la ley $\mathrm{N}^{\mathrm{o}} 1.607$.

La modificación introducida en nuestra normativa obedece, según fue afirmado en la tramitación de la ley en cuestión, a que no resultaba necesario contemplar este tipo de beneficios y garantías especiales, dadas las condiciones generales de estabilidad y conexión internacional del país, a las cuales ya nos referimos.

No obstante ello, este punto suscitó discusión en el Parlamento, indicándose en esa instancia, a modo de ejemplo, que en el Perú no sólo se establece una invariabilidad tributaria, sino que también una que impide el cambio de normas laborales y ambientales, bajo la denominación de "estabilidad jurídica a la inversión extranjera", prevista en su decreto legislativo No 662, de $1991^{58}$.

54 En el informe de la CANIE se deja expresa constancia que esta supresión no contó con la anuencia unánime de todos sus integrantes, ya que algunos de ellos estimaban "necesario que las garantías a la inversión extranjera sean otorgadas mediante la suscripción de un contrato ley entre el inversionista extranjero y el Estado, de características similares al contenido en el DL 600. Se argumenta principalmente que de esta forma se entrega una mayor seguridad al inversionista extranjero, ya que lo estipulado en una ley podría ser modificado posteriormente por otro cuerpo legal. Se señala que los contratos tienen el beneficio de requerir un consentimiento explícito de ambas partes para ser modificados, lo cual incrementa el grado de seguridad para los inversionistas extranjeros, por ejemplo en el caso que en el futuro se incorporen nuevos tributos" (Ministerio de Economía, Informe de la Comisión, 16). Luego, esta temática tampoco logró consensos en la tramitación ante el Congreso (BCN, Historia de la ley $\left.N^{\circ} 20.848,93\right)$.

55 Refiriéndose a la invariabilidad tributaria prevista en el artículo $7^{\circ}$ del decreto ley 600 , durante la discusión de la ley $\mathrm{N}^{\circ}$ 20.780, el Ministro de Hacienda manifestó ante la Cámara de Diputados que "la última empresa que se acogió a la invariabilidad tributaria, a una tasa de 42 por ciento, fue en 1991" (BCN, Historia de la ley $\left.N^{o} 20.780,139\right)$. Planteado este punto en el Senado, el senador Coloma indicó que "respecto de empresas no mineras, el beneficio de la invariabilidad tributaria no se otorga desde el año 2001 por decisión del Comité de Inversiones Extranjeras, que adoptó una política en tal sentido" (BCN, Historia de la ley No 20.848, 96).

56 Paya, Inversión extranjera directa, 198.

57 Véase. Juanita Villaveces y Marcela Anzola, "Análisis crítico de la Ley 963 sobre estabilidad jurídica al inversionista", Borradores de Investigación Economia, 80 (octubre 2005): 1-19.

58 BCN, Historia de la ley $N^{\circ} 20.848,103$.

Sobre este punto, el senador Coloma manifestó "que en Perú existe un estatuto que permite la invariabilidad tributaria y que no se ha planteado cambiar. Consultó por las implicancias que podría tener la toma de decisiones de los inversionistas 
Atendidas las antedichas prevenciones, el artículo segundo transitorio, contempla la posibilidad de que, por hasta 4 años, desde el 1 de enero de 2016, los inversionistas puedan acogerse a un régimen de invariabilidad tributaria, con una tasa total de $44,45 \%{ }^{59}$.

Importante también resulta destacar lo dispuesto en el artículo primero transitorio de la ley de que se trata, que expresa que los inversionistas extranjeros y empresas receptoras de sus aportes que mantengan vigente un contrato de inversión extranjera suscrito con el Estado de Chile, conforme a lo dispuesto en el decreto ley $\mathrm{N}^{\circ} 600$, conservarán íntegramente los derechos y obligaciones contemplados en dichos contratos, en la medida que éstos hayan sido suscritos con anterioridad al 21 de enero de 2016. De igual protección gozan los contratos suscritos en virtud del artículo cuarto transitorio de la ley $\mathrm{N}^{\circ}$ 20.469, que introduce modificaciones a la tributación de la actividad minera, siempre que se hayan celebrado dentro del plazo otorgado por dicha norma.

Para efectos de lo dispuesto en ese artículo, la Agencia de Promoción de la Inversión Extranjera, mantendrá todas las funciones que le correspondían a la Vicepresidencia Ejecutiva del Comité de Inversiones Extranjeras.

\subsection{Estrategia de Fomento y Promoción de la Inversión Extranjera}

En la línea de abandonar lo que se denominó una postura neutral de las autoridades ante la IED, se estableció que el Presidente de la República debe fijar, mediante decreto supremo, expedido a través del Ministerio de Economía, Fomento y Turismo, una Estrategia de Fomento y Promoción de la Inversión Extranjera, a proposición del Comité de Ministros que se crea al efecto.

La mencionada Estrategia debe abarcar, con arreglo al artículo 10, al menos, áreas como la promoción de la inversión extranjera, en especial en sectores o negocios que tengan mayor potencial de desarrollo en Chile; acciones de posicionamiento de nuestro país a nivel internacional, en cuanto a sus recursos y competitividad, y como centro de negocios e inversiones y plataforma global de acceso a otros mercados; facilitar la colaboración entre inversionistas extranjeros y empresas nacionales para el desarrollo y ampliación de actividades productivas en el país, y de las actividades económicas y empresariales de la IED en Chile.

extranjeros en relación con nuestro país, por el hecho de que el citado Estado, que atrae el mismo tipo de inversiones, sí cuente con un mecanismo que garantice invariabilidad tributaria (BCN, Historia de la ley $N^{o} 20.848,93$ ).

Ante esa inquietud, el entonces Vicepresidente Ejecutivo del Comité de Inversiones Extranjeras aseveró que

"efectivamente Perú cuenta con un instrumento similar al decreto ley $\mathrm{N}^{\circ} 600$, solamente para la actividad minera. A lo que se puede sumar el caso de Congo y Zambia. Sin embargo, ni en la OECD ni en otros países mineros, como Australia o Estados Unidos, existe ningún cuerpo normativo siquiera semejante a dicho decreto ley. Sólo cuentan, en el caso de estos dos últimos países, con determinados incentivos tributarios asociados a depreciación acelerada o exenciones de cierto tipo a partir de la cantidad de empleos de calidad que generen. Tal es, entonces, el mercado globalizado en el que Chile debe competir" (BCN, Historia de la ley $\left.N^{\circ} 20.848,97\right)$.

59 El cambio de $42 \%$ a $44,45 \%$ de la tasa de invariabilidad tributaria, obedece a que esa última suma resulta ser consistente con el sistema semi integrado aprobado con la reforma tributaria de la ley $\mathrm{N}^{\circ} 20.780$ (BCN, Historia de la ley $\left.N^{o} 20.848,31\right)$. 
Esta Estrategia debe incluir un diagnóstico de la posición de competitividad internacional del país, una evaluación de la capacidad de la economía para agregar valor en la producción de bienes y servicios a través de la promoción de inversión extranjera, el establecimiento de sus objetivos, las brechas detectadas, y la definición de un conjunto de recomendaciones que considere líneas de acción y metas de mediano y largo plazo.

A juicio de la CANIE, "Chile debe buscar desconcentrar, en forma creciente, tanto el destino (por regiones y/o sectores de la actividad económica) como los países o regiones de origen de los flujos de IED. La diversificación de las inversiones, incluidas las domésticas, debe ser un objetivo central del país si éste busca fortalecer la producción local y los sectores de servicios para hacer la economía menos vulnerable a fluctuaciones económicas externas" ${ }^{\$ 0}$.

Por otra parte, es útil tener presente para estos efectos que la Organización Mundial de Comercio ha constatado que en Chile "la inversión de las empresas en investigación y desarrollo es baja y existe una falta de personal calificado. Las políticas de apertura comercial, acompañadas de las modificaciones al marco regulatorio de la inversión y la adopción de una ley de competencia de mayor alcance, son pasos importantes para mejorar la productividad" ${ }^{\text {. }}$

Teniendo en cuenta todo lo dicho, creemos oportuno expresar que elaborar esta "Estrategia" no es una idea innovadora dentro de nuestro ordenamiento y doctrina, puesto que desde hace mucho encontramos estudios de analistas que han hecho un llamado a potenciar la atracción de inversiones extranjeras enfocadas hacia el sector exportador por medio de políticas públicas $^{62}$.

Así, hace bastantes años se han puesto en práctica, con dispar éxito y alcance, diferentes iniciativas de esta clase, las que deben ser tenidas en cuenta a la hora de formular esta "nueva" herramienta de captación de flujos de capital.

Así por ejemplo, el año 2000, CORFO, mediante su resolución exenta $\mathrm{N}^{\circ}$ 680, de esa anualidad, implementó un Programa de Promoción y Atracción de Inversiones para la Creación de Empresas de Alta Tecnología, habida cuenta de las externalidades positivas que ellas generan en la economía ${ }^{63}$, con el objetivo de diversificar la base productiva nacional y promover la materialización de inversiones en sectores intensivos en nuevas tecnologías ${ }^{64}$.

60 Ministerio de Economía, Informe de la Comisión, 11.

61 OMC, Examen de Politicas Comerciales, Chile, 7.

62 Aníbal Pinto, Chile, una economía difícil (Ciudad de México: Fondo de Cultura Económica, 1964), 128-155; CEPAL, América Latina. El pensamiento de la CEPAL (Santiago: Editorial Universitaria, 1969), 137-162; Óscar Muñoz, "Hacia la reindustrialización nacional", en Reconstrucción económica para la democracia (Santiago: CIEPLAN, Editorial Aconcagua, 1983), 297-348; Alejandro Foxley, Chile y su futuro. Un país posible (Santiago: CIEPLAN, 1987), 80-85

63 Ffrench-Davis, "La inversión extranjera directa en Chile", 298.

64 Manuel Agosin y Juan José Price, "La inversión extranjera ¿Hacia una política vertical? InvestChile: El programa de atracción de inversiones de alta tecnología", en Desarrollo productivo en Chile. La experiencia de Corfo entre 1990 y 2009, edit. Óscar Muñoz (Santiago: Catalonia, 2009), 149. 
Ese programa, que buscaba actuar como una política industrial de tipo vertical (selectiva) siguió de cerca el modelo irlandés de atracción de inversiones extranjeras, contemplando un mecanismo de entrega de subsidios para la puesta en marcha, estudios de preinversión, inversión en activos inmovilizados, arriendo de inmuebles, capacitación y formación de recursos humanos; promoción y marketing, y prestación de servicios al inversionista ${ }^{65}$.

El texto refundido que normaba ese Programa, luego fue aprobado mediante la resolución exenta $\mathrm{N}^{\mathrm{0}}$ 1.094, de 2001, de esa corporación, el que a su vez sufrió sucesivas modificaciones a través de las resoluciones exentas $\mathrm{N}^{\mathrm{o}}$ s. 349 y 716, ambas de 2002, y 145, de 2005, de esa misma entidad.

Luego, mediante la resolución exenta $\mathrm{N}^{\mathrm{0}}$ 1.678, de 2005, se aprobó el nuevo texto del "Reglamento del Programa de Promoción y Atracción de Inversiones de Alta Tecnología", dejando sin efecto el citado anterior reglamento.

Más adelante, a través de las resoluciones $\mathrm{N}^{\circ}$ s. 141 y 292, ambas de 2007, se aprobaron sucesivamente nuevos reglamentos de ese programa.

En tanto, mediante la resolución $\mathrm{N}^{\mathrm{o}} 284$, de 2011, se dejó sin efecto el segundo instrumento recién aludido y se dictó un nuevo reglamento, al cual, en definitiva, se le puso término por medio de la resolución exenta No 1.020, de 2012, de la misma corporación.

Atendida esta secuencia de actos administrativos nos parece sensato señalar que si bien parece plausible estar evaluando constantemente los proyectos, a fin de alcanzar una más eficiente entrega de los recursos involucrados, no resulta acorde con la necesaria certeza y estabilidad de las reglas, el que de manera tan frecuente se estén alterando la reglamentación que normaba ese programa, por lo que a nuestro juicio, en la planificación de la referida Estrategia de Fomento y Promoción, deberán redoblarse los esfuerzos para que ésta tenga perdurabilidad en el tiempo y dé confianza a los actores interesados en invertir en Chile.

Lo anterior, atendido que cuando las empresas no están seguras acerca del régimen jurídico existente en un país o las reglas dadas son poco transparentes, ellas tienden a sobrestimar los riesgos asociados a aquél, incluso más allá de la realidad ${ }^{66}$.

En este orden de ideas, parece necesario que se aprovechen de mejor forma los distintos esfuerzos vinculados a la producción que está desarrollando CORFO -en industria proveedora de bienes de capital, insumos intermedios y servicios a la minería; el sector de alimentos; y el sector turismo ${ }^{67}$-, a fin de que se estimule que la IED pueda colaborar en esos procesos, y

Agosin y Price, "La inversión extranjera", 150-156.

66 Fernández Rozas, Sistema de Derecho Económico Internacional, 378.

67 Ministerio de Economía, Informe de la Comisión, 9. 
también con las distintas iniciativas que forman parte de la Agenda de Productividad, Innovación y Crecimiento ${ }^{68}$.

Sobre el particular, a nuestro juicio, dentro de las áreas en que debiese centrar sus esfuerzos están las vinculadas a potenciar el uso de energías renovables, como por ejemplo la solar ${ }^{69}, \mathrm{y}$ seguir perfeccionando la infraestructura del país.

Asimismo, se ha sugerido ${ }^{70}$ que la política a implementar sobre la materia debiera canalizarse hacia la innovación productiva, empleando para ello, a modo de ejemplo, joint ventures, que pongan en contacto a firmas líderes en la producción de ciertos bienes a nivel mundial con actores locales.

Dicho lo anterior, nos parece importante recalcar que un reto interesante de afrontar es acortar la brecha de productividad que aún mantiene Chile en relación con los países desarrollados, para lo cual es necesario mantener eficientes políticas económicas, que entre otros aspectos mejoren el capital humano, que hoy actúa como obstáculo para alcanzar ese objetivo ${ }^{71}$.

La promoción de exportaciones debe conjugar políticas fiscales, financieras, monetarias e industriales con el objeto de incentivar el aparato productivo hacia nuevos mercados, aprovechando las ventajas con que se cuente en mano de obra, disponibilidad de materias primas y habilidad o conocimiento tecnológico. En la formación de estas políticas debe oírse y dar espacio para participar a las empresas, a fin de que ellas adquieran nuevas técnicas de comercialización, gestión y asociación o reestructuración ${ }^{72}$, además de las universidades y centros de formación, y las instituciones sociales intermedias, que también deben coadyuvar en su elaboración.

Con todo, nos vemos en la necesidad de advertir que en la actualidad, exitosas políticas que fomentaron la generación de tecnologías y la industrialización local, por vía de medidas activas de promoción de las exportaciones, tales como aquellas que se verificaron en países como Corea y Japón, entre los años cincuenta y ochenta, hoy se encuentran con la limitación de los compromisos asumidos por los países, entre ellos Chile, en el marco de la regulación a las subvenciones estatales de la $\mathrm{OMC}^{73}$.

\footnotetext{
68 BCN, Historia de la ley $N^{0} 20.848,97$.

BCN, Historia de la ley $N^{\circ} 20.848,95-96$.

Ffrench-Davis, "La inversión extranjera directa en Chile", 312-314.

Corbo, "Chile: el progreso y las oportunidades", 65.

2 Aníbal Sierralta, Contratos de Comercio Internacional (Lima: Fondo Editorial Pontificia Universidad Católica del Perú, 2004), 41-51.

73 Singh, "IED, Globalización y Desarrollo”, 20-31; Rodríguez y Sánchez, "Derecho de los negocios internacionales”, 87-88.
} 


\subsection{Comité de Ministros para el Fomento y Promoción de la Inversión Extranjera ${ }^{74}$}

Este cuerpo colegiado, presidido por el Ministro de Economía, Fomento y Turismo, e integrado también por los Ministros de Hacienda y demás secretarios de Estado que, con carácter permanente, determine el Presidente de la República, tiene por objeto asesorar al Jefe de Estado en distintas materias vinculadas al fomento y promoción de la inversión extranjera.

En el cumplimiento de su objeto este organismo, de acuerdo con el artículo 12, tiene, entre otras, las siguientes funciones y atribuciones ${ }^{75}$.

i) Proponer al Presidente de la República la anotada Estrategia de Fomento y Promoción de la Inversión Extranjera.

La que a su vez, de acuerdo con lo previsto por el $\mathrm{N}^{\circ} 4$ del artículo 16 es propuesta por la Agencia, que se analizará en breve.

ii) Definir, conforme a lo propuesto por la citada Agencia los planes, programas y prioridades destinados a la implementación de la aludida Estrategia de Fomento.

iii) Velar por la debida coherencia entre la mencionada Estrategia y las medidas y acciones implementadas por la Agencia.

iv) Velar por la coordinación de los distintos órganos del Estado vinculados a la implementación de la mencionada Estrategia de Fomento.

En el ejercicio de esta facultad, puede encomendar a la Agencia que coordine las acciones de promoción y atracción de IED que realicen los gobiernos regionales.

Vinculado con ello, es menester recordar que, en paralelo, existen diferentes órganos que también se dedican a estas materias, como por ejemplo, la Dirección General de Relaciones Económicas Internacionales (DIRECON), del Ministerio de Relaciones Exteriores; ProChile, que posee representantes en el extranjero, e Imagen de Chile, que se dedica a la promoción, además de entidades regionales y comunales, entre otros.

En el caso que se cumpla eficazmente el rol de coordinación encomendado, se podrá atenuar lo que Felipe Herrera ${ }^{76}$ llamaba el "feudalismo administrativo" presente en nuestro país, que impide un aprovechamiento adecuado de las energías y recursos destinados a

\footnotetext{
74 Dentro de los motivos que fundamentan la creación de esta nueva entidad podemos mencionar la conclusión a que se llegó en la CANIE, en orden a que hasta la fecha la estrategia chilena de promoción de la IED había sido pasiva, limitándose a informar, en términos genéricos, los principales atributos con que cuenta el país (Ministerio de Economía, Informe de la Comisión, 6).

75 Bastante se discutió en la Cámara Alta, tanto por senadores de gobierno como de oposición, respecto a las atribuciones que se le brindaban al comité de ministros en análisis, ya que se estimaba que al quedar como una instancia meramente propositiva se diluía su poder efectivo (BCN, Historia de la ley $N^{o} 20.848,161$ - 166).

76 Felipe Herrera, Chile en América Latina (Santiago: Zig zag, 1969), 50.
} 
unos mismos objetivos, que cumplen simultáneamente diferentes organismos integrantes del aparataje estatal.

v) Evaluar la implementación de la Estrategia y del resto de los planes y programas vinculados a la promoción y fomento de la inversión extranjera.

\subsection{Agencia de Promoción de la Inversión Extranjera ${ }^{77}$}

De acuerdo con el artículo 15, esta entidad -continuadora y sucesora legal del Comité de Inversiones Extranjeras ${ }^{78}$ - es un servicio público descentralizado, con personalidad jurídica y patrimonio propio, domiciliado en la ciudad de Santiago ${ }^{79}$, que se relaciona con el Presidente de la República por intermedio del Ministerio de Economía, Fomento y Turismo.

Su finalidad se detalla en el inciso tercero de ese mismo precepto, en el cual se indica que esta institución debe promover y atraer el ingreso de todo tipo de capitales e inversiones del exterior, sin importar su monto, conforme a las facultades y atribuciones señaladas en esa ley. En el ejercicio de tales atribuciones debe establecer las instancias de coordinación que le encomiende el Comité de Ministros y que sean necesarias para implementar la Estrategia de Fomento, velando por la coherencia de las acciones de promoción y atracción de las inversiones que realicen los gobiernos regionales ${ }^{80}$.

De acuerdo con lo expresado por el Ministro de Economía, Fomento y Turismo, en la tramitación del proyecto de ley ${ }^{81}$, se justifica la creación de este servicio dado que:

i. Es un organismo especializado y dedicado íntegramente a la promoción y atracción de IED, que da a conocer a los potenciales inversionistas los atributos y ventajas de invertir en el país; les entrega asistencia y seguimiento, lo que facilita la decisión de dónde invertir, y permite separar los esfuerzos de promoción y atracción de IED con los esfuerzos de promoción de exportaciones.

77 Esta entidad sigue los lineamientos que sobre la materia ha dado la OCDE, y busca enfocar la inversión extranjera hacia sectores estratégicos o carentes de inversión, debido a fallas de mercado (BCN, Historia de la ley $\left.N^{o} 20.848,4,5,26\right)$.

78 Respecto a esa institución se señaló que aquella era más "un receptor de inversión que un promotor de la misma” (BCN, Historia de la ley $N^{\circ} 20.848$, 94).

79 En lo que atañe al carácter descentralizado de este organismo, cabe advertir que ésta se trata de descentralización funcional, no territorial, puesto que esta Agencia quedó concebida para operar sólo en la capital, lo que fue objeto de críticas, puesto que algunos parlamentarios plantearon que hubiera sido positivo que esa entidad estuviere descentralizada a nivel regional y contara con oficinas en cada una de las capitales de esas unidades territoriales (BCN, Historia de la ley $N^{\circ}$ $20.848,29)$.

80 Es útil tener presente que la redacción original del proyecto de ley contemplaba a esta agencia como el "único organismo autorizado para promover y atraer el ingreso de todo tipo de capitales e inversiones del exterior" [todo ello con arreglo a sugerencia de la CANIE, que al efecto recogió las propuestas de la OCDE sobre el particular (Ministerio de Economía, Informe de la Comisión, 13)]. Sin embargo, ese tenor fue objetado en el Senado, que vio en aquella redacción una inhabilitación para que intendentes, gobiernos regionales, alcaldes o los propios parlamentarios puedan llevar a cabo gestiones conducentes a estimular o fomentar inversión extranjera en el plano territorial correspondiente (BCN, Historia de la ley $\left.N^{0} 20.848,167-187\right)$.

81 BCN, Historia de la ley $N^{\circ} 20.848,27$. 
Nuevos escenarios para la inversión extranjera en Chile Javier Gallegos Zúñiga

ii. Diversos estudios demuestran que las agencias de este tipo mejoran la cantidad y calidad de la IED.

iii. Actualmente más de 170 países cuentan con instituciones de esta clase ${ }^{82}$.

A juicio de la CANIE "Chile requiere la creación de una agencia moderna, dinámica, empoderada, coherente con las mejores prácticas internacionales y que cuente con la infraestructura, cobertura geográfica y con los recursos humanos, tecnológicos y financieros necesarios para llevar a cabo en forma eficiente y eficaz la labor de promoción, atracción y facilitación de IED de alto impacto, tanto en términos de volumen como de calidad. La agencia debe contar con un mandato claro, enfocado en su etapa inicial a realizar acciones concretas para construir su credibilidad y competencia" ${ }^{\$ 3}$.

Este tipo de entidades, ya hace bastante se había recomendado como una alternativa, siguiendo los lineamientos del Derecho comparado ${ }^{84}$, a objeto de que se contase con una entidad que se abocase, de manera más activa, para la promoción de Chile como un Estado receptor de las inversiones extranjeras.

Sus atribuciones y funciones figuran en el artículo 16, entre las cuales destacan:

a) Implementar la Estrategia de Fomento, a través de medidas y acciones de promoción de la inversión extranjera en Chile (las que deben ser evaluadas regularmente y aprobadas por el Comité de Ministros).

Asimismo, en el marco de las medidas definidas por el referido Comité, la Agencia puede:

i) Organizar misiones públicas o privadas de potenciales inversionistas extranjeros hacia Chile y participar en ellas, promoviendo las bondades de la inversión extranjera en el país, así como gestionar y formar parte en rondas de negocios, ferias, seminarios, foros y misiones de promoción del país, para atraer inversión extranjera, las que podrán realizarse tanto dentro como fuera de él.

ii) Brindar orientación e información a los potenciales inversionistas extranjeros sobre el mercado, la legislación y los incentivos aplicables a su inversión, así como informarles de otros aspectos relevantes para su inversión ${ }^{85}$.

\footnotetext{
A su vez, hay más de 260 entidades de este tipo a nivel subnacional (Ministerio de Economía, Informe de la Comisión: 12). Ministerio de Economía, Informe de la Comisión, 12.

Rodríguez, Régimen de la inversión extranjera, 185-187.

85 Detallando este tipo de labores en la CANIE se manifestó que labores de esta naturaleza son: “(i) provisión de servicios de información y manejo y respuestas a requerimientos de potenciales inversionistas; (ii) provisión de servicios de facilitación, a través de su interacción con reparticiones gubernamentales y asociaciones y gremios claves del sector privado, con el objeto de prestar un servicio efectivo de solución a los problemas y requerimientos de los inversionistas y de apoyo a la materialización de su inversión; y (iii) provisión de servicio de after-care, área fundamental debido a la relevancia de la reinversión dentro de los flujos de IED y a la capacidad de trabajar con inversionistas existentes tanto en el mejoramiento del marco de las políticas públicas existentes como en actividades promocionales o testimoniales" (Ministerio de Economía, Informe de la Comisión, 13).
} 
iii) Realizar actividades destinadas a retener y estimular la expansión y la reinversión de la inversión extranjera que se haya materializado en el país, con el fin de lograr mayor impacto económico local de la misma.

iv) Colaborar con los inversionistas extranjeros en la generación de contactos y reuniones con entidades de Gobierno, gremios económicos, empresarios, proveedores, instituciones financieras, centros de investigación y otros actores que faciliten el ingreso de la inversión extranjera a Chile.

v) Constituir un Consejo Asesor Consultivo conformado por representantes de los sectores público y privado, que tendrá por misión asesorar al Director en la definición de objetivos de mediano y largo plazo, así como evaluar las actividades, las iniciativas y los esfuerzos desplegados por la Agencia.

Aquel Consejo debe considerar la participación permanente de un representante de la Subsecretaría de Desarrollo Regional ${ }^{86}$, y también del Presidente del Gobierno Regional respectivo en las sesiones en que se analicen actividades, iniciativas o esfuerzos vinculados a la región correspondiente.

vi) Promover a Chile como destino de inversión ${ }^{87}$.

vii) Toda otra actividad que contribuya a la promoción de la inversión extranjera en Chile.

b) Actuar como órgano administrativo del Comité de Ministros, para lo cual debe recibir y analizar las presentaciones que se le hagan, generar los antecedentes y estudios que requiera y desarrollar toda otra función de carácter administrativo que determine ese Comité.

c) Conocer de las solicitudes de certificación sobre la calidad de inversionista extranjero y emitir los certificados que corresponda.

d) Proponer al Comité de Ministros la Estrategia de Fomento y Promoción de la Inversión Extranjera.

e) Contribuir a crear un clima favorable para la inversión extranjera en Chile, en particular identificando obstáculos a la materialización de proyectos de inversión extranjera e

86 La incorporación del representante del la Subsecretaría de Desarrollo Regional obedeció a una indicación que presentó el Ejecutivo, con ocasión a los requerimientos que diferentes parlamentarios formularan en orden a potenciar el rol de las regiones en el ámbito de la promoción de la inversión extranjera (BCN, Historia de la ley $\left.N^{\circ} 20.848,188\right)$.

87 Sobre este particular la CANIE expresó que debiese ponerse especial atención de atraer inversión extranjera de determinados países que son importantes exportadores de capital -a nivel global- pero no invierten en forma importante en Chile, como Alemania, China y Francia, y también de otros de la región con alto potencial de IED en Chile como Brasil y Colombia (Ministerio de Economía, Informe de la Comisión, 13). 
informando de ellos a las autoridades competentes, con el fin de avanzar en su superación ${ }^{88}$.

Esto puede relacionarse con lo que se ha denominado el establecimiento de una "ventanilla única" 89 para el inversionista extranjero, que facilite los diferentes trámites e interacciones con las autoridades locales.

f) Recopilar, registrar y sistematizar información y estadísticas en inversión extranjera. Con este objeto puede requerir, tanto a organismos públicos como privados y a los propios inversionistas extranjeros, la información pertinente para el cumplimiento de esta función.

Con igual fin, la Agencia debe utilizar las estadísticas macroeconómicas sobre inversión extranjera que compile y publique el Banco Central de Chile ${ }^{90}$, para lo cual puede suscribir con ese organismo los convenios o acuerdos de colaboración que garanticen una adecuada y efectiva coordinación en ese ámbito.

g) Informar anualmente al Comité de Ministros acerca de los avances en el cumplimiento de la Estrategia de Fomento.

Como queda constancia de la historia de la ley ${ }^{91}$, esta Agencia paulatinamente requerirá ir incrementando los gastos vinculados a su quehacer, asociados a atraer y promover la inversión extranjera al país, contemplando, entre otras medidas, el establecimiento de agregados de inversiones en el extranjeros, para cuatro países definidos como socios estratégicos, cuales son Estados Unidos, China, Alemania y España.

En paralelo, cabe tener presente que en la tramitación parlamentaria se agregó al proyecto original presentado por el Gobierno, un nuevo artículo, que en definitiva pasaría a ser el 21, en cuyo mérito se habilita a los gobiernos regionales, para que con sus propios recursos, puedan organizar unidades de promoción y atracción de inversión extranjera ${ }^{92}$.

Sobre esta temática, cabe recordar que la ley $\mathrm{N}^{0} 19.175$, orgánica constitucional sobre gobierno y administración regional, en su artículo 100 -dentro del capítulo denominado Asociativismo regional- permite a los gobiernos regionales constituir corporaciones o fundaciones, que, entre otras medidas, pueden realizar estudios orientados a identificar áreas o sectores con potencial de crecimiento, estimular la ejecución de proyectos de inversión, fortalecer la capacidad

88 Sobre esta materia paradigmático resulta ser, en un análisis perspectivo, la decisión de INTEL de no materializar sus proyectos de una planta en Chile e implementar ese proyecto en Costa Rica, que en su momento se debió a las trabas y obstáculos que presentaba la regulación y las entidades públicas atingentes. Vid. Ffrench-Davis, "La inversión extranjera directa en Chile", 298.

89 BCN, Historia de la ley $N^{o} 20.848,138$.

90 Sobre este punto, es útil recordar que de conformidad con lo previsto en el artículo 53 de la Ley Orgánica Constitucional del Banco Central de Chile, esa entidad debe "compilar y publicar, oportunamente, las principales estadísticas macroeconómicas nacionales, incluyendo aquellas de carácter monetario y cambiario, de balanza de pagos y las cuentas nacionales u otros sistemas globales de contabilidad económica y social".

91 BCN, Historia de la ley $N^{0} 20.848,15,25,66$.

92 BCN, Historia de la ley $N^{0} 20.848,, 44,58,82$. 
asociativa de pequeños y medianos productores, promover la innovación tecnológica, incentivar las actividades artísticas y deportivas, estimular el turismo intrarregional, mejorar la eficiencia de la gestión empresarial y efectuar actividades de capacitación.

\section{Conclusiones}

Como ha tenido ocasión de exponerse, el nuevo estatuto de la inversión extranjera previsto en la ley $\mathrm{N}^{\mathrm{0}}$ 20.848, supone un quiebre en la manera misma de afrontar la posición del Estado frente al inversionista foráneo, inspirado en una actitud consciente de las potencialidades y cualidades del país, que en esa lógica, buscará seguir incrementando cuantitativamente y cualitativamente la IED que reciba Chile.

En momentos de inquietud económica, la apuesta de las autoridades chilenas puede aparecer algo riesgosa, más aún si recogemos algunas publicaciones de la prensa ${ }^{93}$ que dan cuenta de un retroceso en la cuantía de la inversión extranjera en el país el año 2015 en un 46\% respecto de 2014.

Sin embargo, estimamos que el panorama económico actual debe servirnos como desafío estimulante para que las autoridades competentes gesten una Estrategia de Promoción y Estímulo de la Inversión Extranjera Directa inteligente y creativa, que tomando en cuenta y ponderando las anteriores iniciativas análogas emprendidas en Chile y en el Derecho comparado, nos permitan mantener la posición de liderazgo a nivel regional y mundial en la atracción de estos flujos de recursos.

Para lo dicho, no podemos perder de vista, que hay una serie de estudios que han concluido que determinantes en la atracción de IED en un país son su nivel de renta per capita, su tasa de crecimiento, y su infraestructura de capital físico y humano ${ }^{94}$. Si Chile incrementa esos índices, nos encontraremos en un círculo virtuoso, que redundará positivamente en el bienestar de su población y al mismo tiempo servirá de estímulo para captar más capitales foráneos.

Por ello, manos a la obra, la elaboración de esa Estrategia debe afrontarse de la mejor manera, después de muchos años de ir y venir con ese postulado, ¡Ahora es cuando!

93 "Veo un impacto en los flujos de inversión hacia Chile por contagio de Brasil", El Mercurio, 1 de marzo de 2016, B6; "Si los precios de las materias primas siguen abajo, sería iluso pensar que vamos a volver a cifras de US\$20.000 millones”, El Mercurio, 29 de febrero de 2016, B4.

94 Singh, "IED, Globalización y Desarrollo", 32. 